\title{
Risks of Skin, Hair, and Nail Supplements
}

\author{
Emily K. Burns ${ }^{1}$, Ariadna Perez-Sanchez ${ }^{2}$, Rajani Katta ${ }^{3}$
}

1 Baylor College of Medicine, Houston, TX, USA

2 Department of Internal Medicine, University of Texas Health Science Center, San Antonio, TX, USA

3 Department of Dermatology, McGovern Medical School at UT Health, Houston, TX, USA

Key words: dietary supplements, nutrition, diet, toxicity, adverse effects

Citation: Burns EK, Perez-Sanchez A, Katta R. Risks of skin, hair, and nail supplements. Dermatol Pract Concept. 2020;10(4):e2020089. DOI: https://doi.org/10.5826/dpc.1004a 89

Accepted: May 28, 2020; Published: October 26, 2020

Copyright: (92020 Burns et al. This is an open-access article distributed under the terms of the Creative Commons Attribution License BYNC-4.0, which permits unrestricted noncommercial use, distribution, and reproduction in any medium, provided the original author and source are credited

Funding: None.

Competing interests: Rajani Katta, MD serves on the Advisory Board for Vichy Laboratories and is the author of a book for the general public on dermatology.

Authorship: All authors have contributed significantly to this publication.

Corresponding author: Rajani Katta, MD, 6800 West Loop South Suite 180, Bellaire, TX 77401, USA. Email: info@kattamd.com

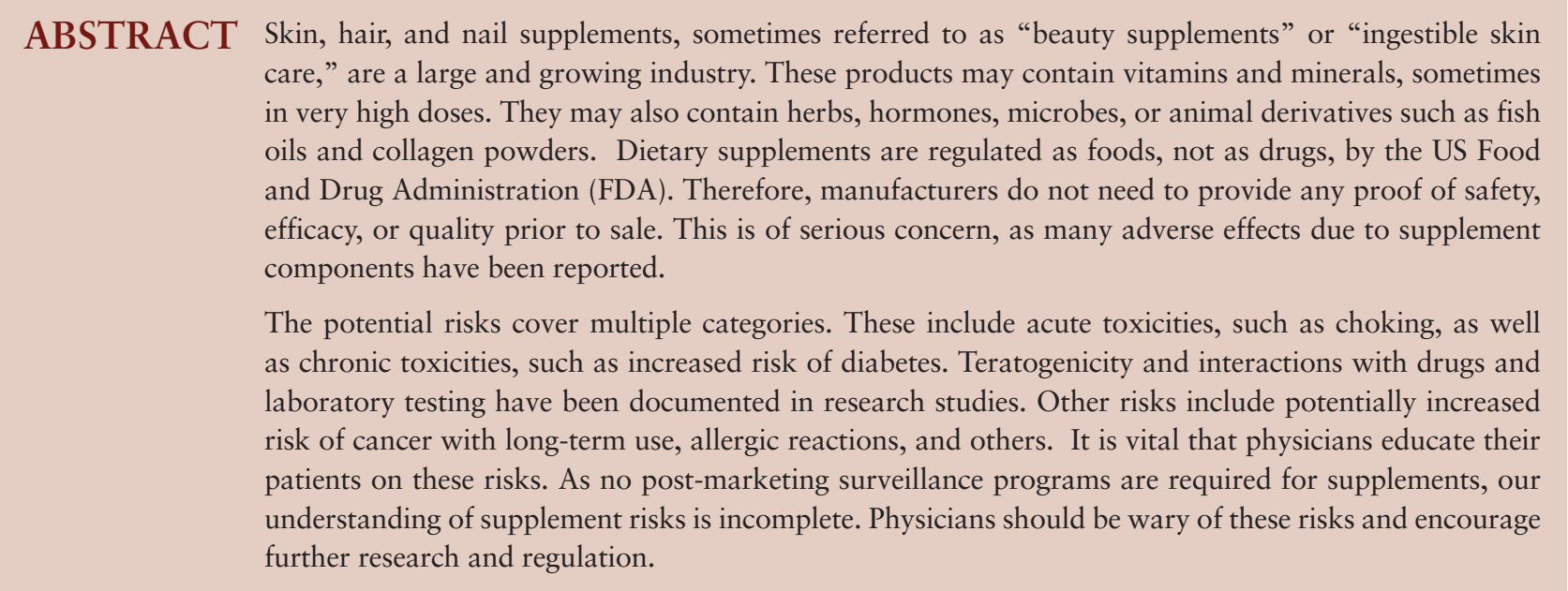

\section{Introduction}

Skin, hair, and nail supplements have become a large and growing industry in the United States and worldwide. Sometimes referred to as "beauty supplements" or "ingestible skin care," these dietary supplements continue to increase in popularity. They are frequently promoted on social media and by celebrities, sometimes as "natural" alternatives to cosmetic procedures. These products are sold online and in stores (Figure 1). Dietary supplements in general are widely used, with reports indicating that approximately half of US adults report using dietary supplements [1-4]. The global beauty supplement market was valued at $\$ 3.5$ billion in 2016 and is projected to grow to $\$ 6.8$ billion by the end of 2024, according to a report by Goldstein Research [5]. As more patients, such as those with androgenetic alopecia or 


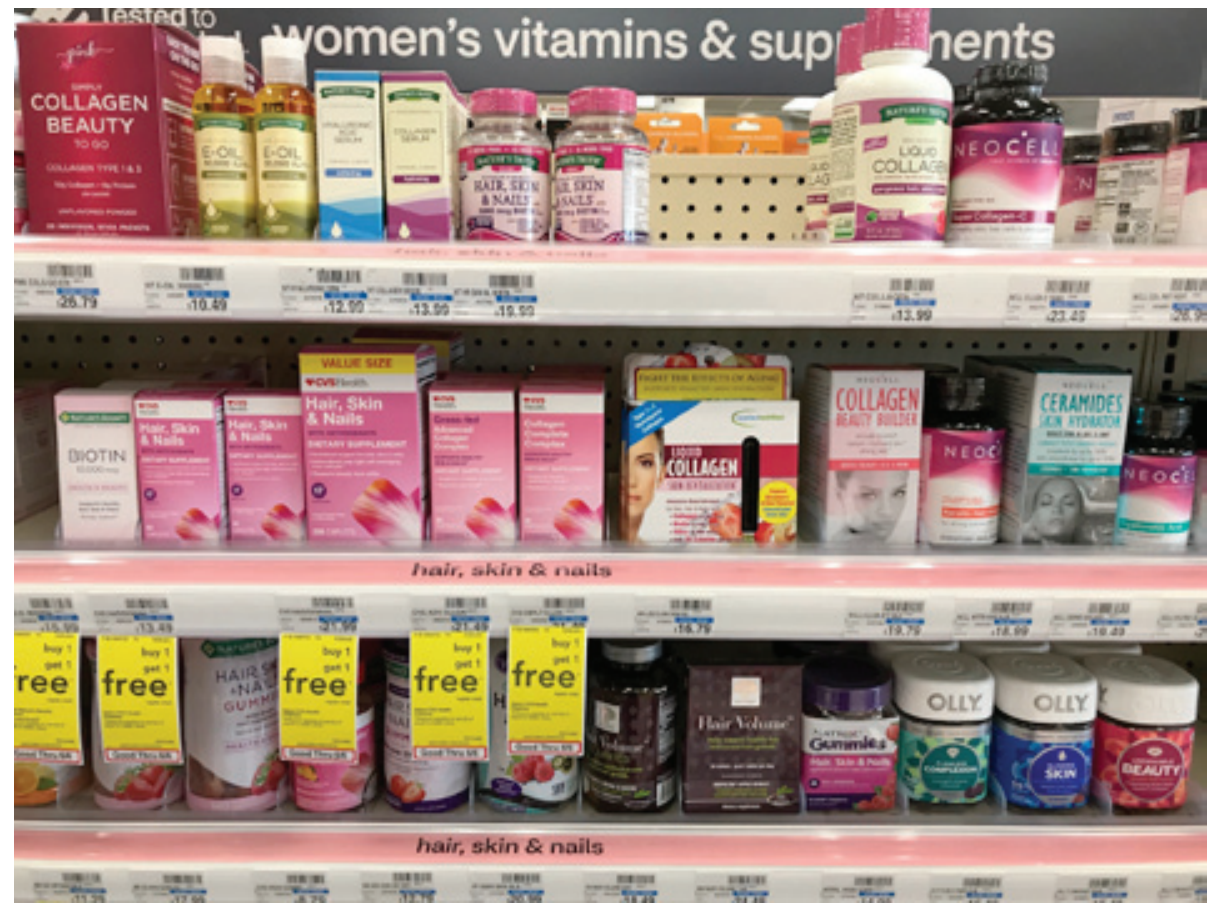

Figure 1. Multiple skin, hair, and nail supplements available for sale at a local retailer.

brittle nails (Figures 2 and 3), express an interest in these supplements, it is imperative that dermatologists be able to answer their questions and provide guidance based on the medical literature. An overview of the potential risks is especially vital.

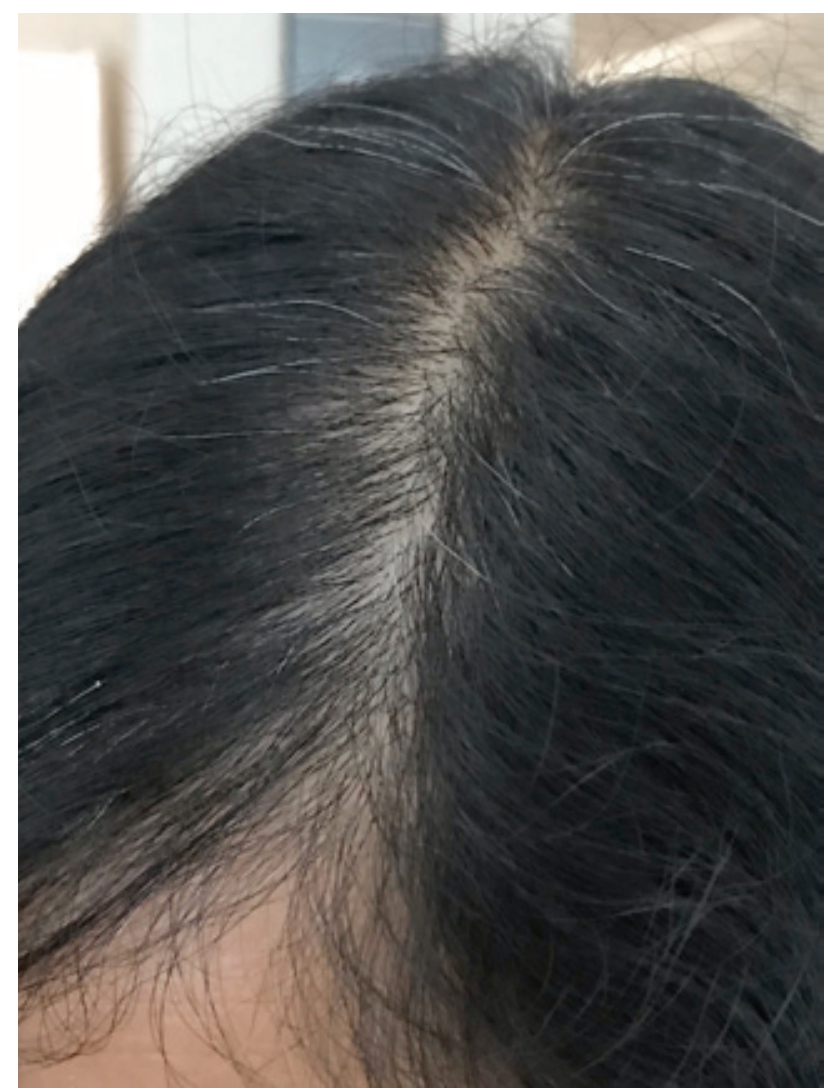

Figure 2. Patients with androgenetic alopecia, seen here with a widened part, may inquire about the use of skin, hair, and nail supplements.
The category of skin, hair, and nail supplements includes many different ingredients, and educating patients on the potential risks of these ingredients is especially important. Vitamins are frequent ingredients, such as vitamins A, C, and multiple B vitamins, as well as minerals such as zinc and

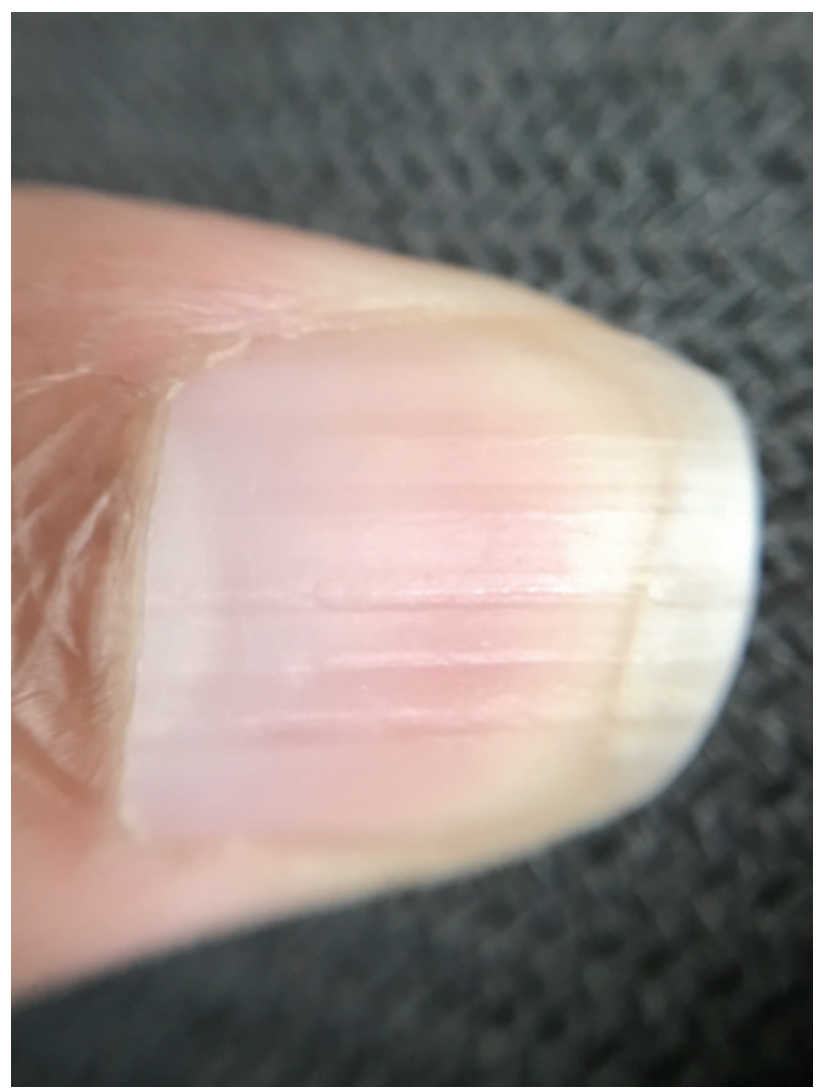

Figure 3. Patients with brittle nails may inquire about the use of nail supplements. 
selenium. Some of these nutrients are included in supplements at very high doses (Figures 4 and 5). Herbal ingredients such as saw palmetto are common as well. Food components are included in this category, such as collagen powders and fish oils. Even hormones and microbes are marketed as having beneficial skin effects, including melatonin and probiotics [5].

The dietary supplement industry has minimal oversight from the US FDA. Supplements are regulated as foods, not as drugs, which has multiple implications in terms of safety and oversight [6,7]. By law, manufacturers of dietary supplements do not require approval by the FDA before launching a new product [8]. In essence, any company can bring to market a dietary supplement without having to first provide any evidence of efficacy or safety. Multiple vitamins, minerals, herbs, and other substances may be combined without having to first test for compatibility or interactions.

In addition, FDA requirements on warning labels are minimal [6]. Supplements with iron must warn about overdosing and poisoning in children [9]. If a manufacturer includes a structure/function claim on a supplement label, then they must also include a statement or "disclaimer." This disclaimer indicates that the structure/function claim has not been evaluated by the FDA and that "this product is not intended to diagnose, treat, cure, or prevent any disease" [8]. Other warning requirements are lacking. There is no

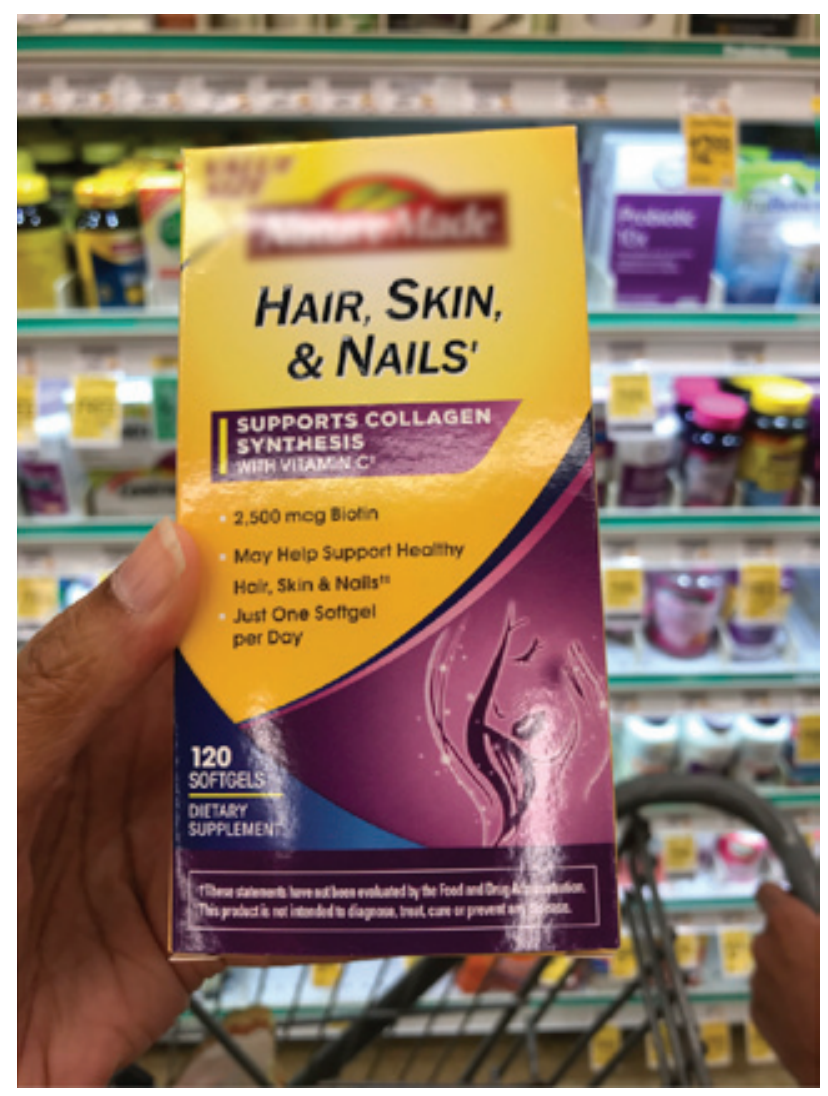

Figure 4. Example of a skin hair, and nail supplement, seen here with a health claim and a disclaimer.

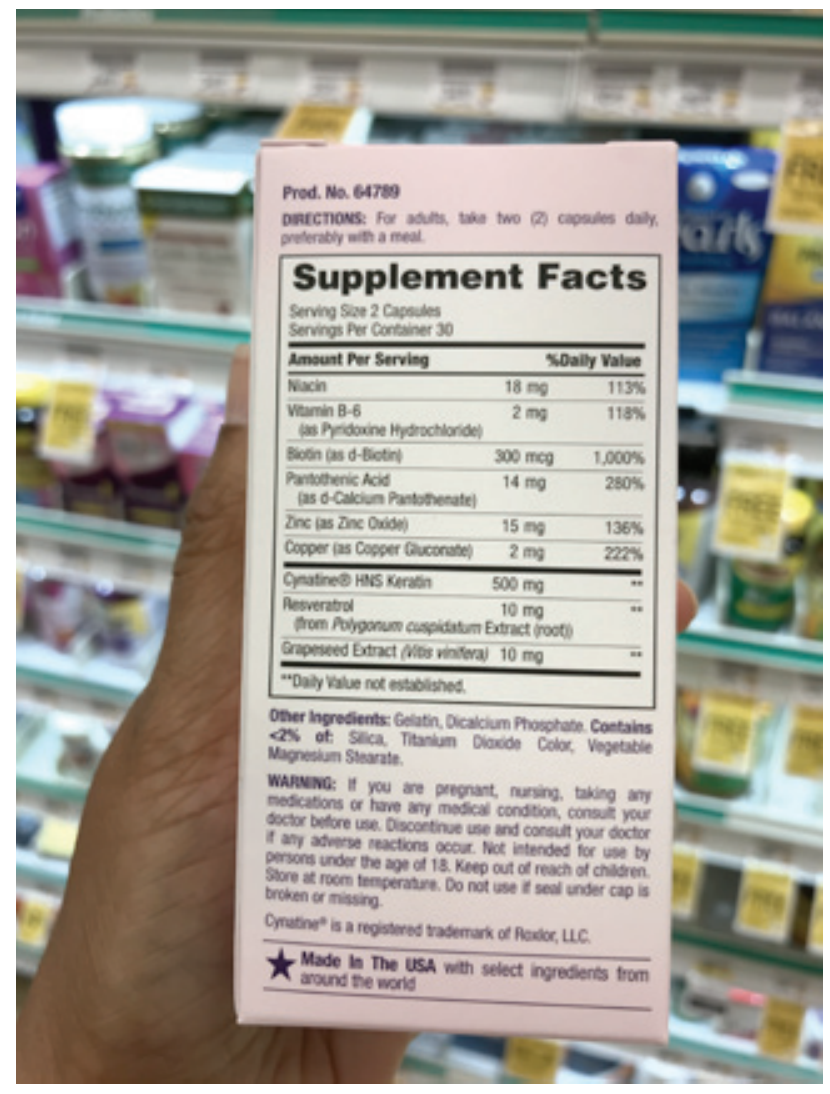

Figure 5. Example of the Supplement Facts label for a skin, hair, and nail supplement.

required warning label indicating risk of teratogenicity, even when demonstrated in research studies. The same applies to interactions with medications and laboratory tests, even when documented by research.

In this review, we describe several categories of potential risks posed by skin, hair, and nail supplements. In discussing these risks, physicians must emphasize to their patients the importance of multiple variables that impact how an individual may react to a particular supplement. These variables include age, the use of other medications, underlying medical conditions, differences in metabolism, and others.

We emphasize that there are a number of other risks not discussed here. Of special concern are those risks that may be severe but infrequent. Such risks may only be discovered in post-marketing surveillance programs. The supplement manufacturer is solely responsible and lacks supervision for ensuring pre-marketing safety and efficacy. Research and documentation of these parameters is completely optional. Similarly, post-marketing surveillance by the manufacturer is not required. Instead, it relies on reports from consumers, health care professionals, and industry members. In other words, the FDA does not actively monitor new dietary supplements, leading to a large gap in our knowledge of supplement safety. 


\section{Acute Toxicities}

A number of acute toxicities have been reported (Table 1). Reports indicate over 23,000 emergency department visits annually in the U.S. for supplement adverse events [10]. Among adults $\geq 65$, pill-induced dysphagia or choking was associated with $37.6 \%$ of all emergency department visits for supplement adverse events, with micronutrients implicated in over $80 \%$ of cases [10]. The FDA recommends a pharmaceutical tablet size of less than $22 \mathrm{~mm}$ and requires reporting of tablet size on all new drug applications. By contrast, supplements do not have reporting requirements or size recommendations. Many products available in stores exceed $22 \mathrm{~mm}[10,11]$.

Melatonin, a hormone sometimes marketed for "beauty" sleep, carries a risk of sedation and may increase fall risk. In one trial, a single $3-\mathrm{mg}$ dose resulted in impaired postural control in older adults [12].

In terms of physiologic effects, high doses of vitamin $\mathrm{C}$ have been associated with the formation of calcium oxalate kidney stones, particularly in patients with impaired renal function [13,14]. High doses have also been associated with acute hemolysis in those with G6PD deficiency [15]. High doses of B6 and B12 have been associated with the development of rosacea fulminans [16].

\section{Chronic Toxicities}

Hair loss supplements may contain a number of different ingredients, including the minerals iron and selenium. Although supplemental iron has not shown benefit for hair loss in those with normal levels, iron is frequently found in dietary supplements advertised for hair loss [17]. The long-term use of iron in those who are not deficient, even at low doses, has resulted in symptoms of iron overload [18]. Common adverse effects of iron overdose are constipation, gastrointestinal upset, reduced zinc uptake, and iron overload in hemochromatosis [19].

Long-term selenium use is also concerning. Although the upper tolerable intake is $400 \mu \mathrm{g}$ per day, concerns have been raised at $200 \mu \mathrm{g}$ per day, a dose found in some hair loss supplements [20]. One randomized controlled trial (RCT) examined the effects of different doses of selenium as compared to a placebo in a country with moderately low selenium status at baseline. Researchers found that a $300 \mu \mathrm{g}$ per day dose of selenium ingested daily for 5 years increased all-cause mortality as assessed 10 years later [21]. Epidemiological studies have raised concern as well. Multiple studies have noted that high plasma selenium levels may be associated with increased prevalence of type 2 diabetes, hyperglycemia, and dyslipidemia [22-24]. Selenium may also increase the incidence of type 2 diabetes. One RCT found that $200 \mu \mathrm{g}$ per day in non-diabetic patients (average age of 63 years and average follow-up of 7.7 years) significantly increased risk for development of type 2 diabetes as compared to placebo [25]. Importantly, an exposure-response gradient was found across subgroups of plasma selenium levels [25]. In patients with preexisting type 2 diabetes, administration of selenium for 3 months resulted in statistically significant elevations in serum glycosylated hemoglobin A1c (HbA1c) levels, as well as fasting plasma glucose [26].

\section{Risk of Nutrient Overconsumption From Supplements With Dietary Sources}

Another challenge with the use of dietary supplements is the parallel consumption of food (Table 2). Nutrients are derived from both supplements and foods, and this is a concern for certain nutrients. The US Food and Nutrition Board has published upper tolerable limits for 24 nutrients

Table 1. Acute and Chronic Toxicities Due to Skin, Hair, and Nail Supplements (Selected Examples)

\begin{tabular}{|l|l|}
\hline \multicolumn{2}{|c|}{ Acute Toxicity } \\
\hline Dysphagia or choking, particularly among adults $\geq 65[10]$ & Tablet size $>22 \mathrm{~mm}$ \\
\hline Sedation and falling risk [12] & Melatonin \\
\hline $\begin{array}{l}\text { Calcium oxalate kidney stones [13,14] } \\
\text { Acute hemolysis in patients with G6PD deficiency [15] }\end{array}$ & High-dose vitamin C \\
\hline Rosacea fulminans [16] Chronic Toxicity & $\begin{array}{l}\text { High-dose vitamin B6 } \\
\text { High-dose vitamin B12 }\end{array}$ \\
\hline \multicolumn{1}{|c|}{ Constipation, gastrointestinal upset, reduced zinc uptake [18,19] } & High-dose iron \\
\hline $\begin{array}{l}\text { Increased all-cause mortality [21] } \\
\text { Increased incidence of type 2 diabetes, dyslipidemia, and } \\
\text { hyperglycemia [22-25] }\end{array}$ & High-dose selenium \\
\hline
\end{tabular}


Table 2. Adverse Effects due to Skin, Hair, and Nail Supplements (Selected Examples)

\begin{tabular}{|l|l|}
\hline Interaction & \\
\hline $\begin{array}{l}\text { Lab testing: thyroid-stimulating hormone, troponin, b-hCG and } \\
\text { NT-proBNP tests [30-33] }\end{array}$ & Biotin (vitamin B7) \\
\hline Warfarin (leading to risk of increased bleeding) [34-36] & Saw palmetto \\
\hline Teratogenicity & \\
\hline Ambiguous genitalia in male offspring [38] & Saw palmetto (5-alpha-reductase inhibitor) \\
\hline Birth malformations [41-43] & High-dose vitamin A \\
\hline Allergic Reactions & \\
\hline Anaphylaxis [52] & Hydrolyzed fish collagen \\
\hline Drug reaction with eosinophilia and systemic symptoms [48] & Diindolylmethane (DIM) \\
\hline $\begin{array}{l}\text { Urticarial reactions, fixed drug reactions, generalized dermatitis, } \\
\text { anaphylaxis [50,51] }\end{array}$ & Dyes and preservatives used in supplements \\
\hline Increased Cancer Risk & $\begin{array}{l}\text { Antioxidant supplement (vitamin C, vitamin E, beta- } \\
\text { carotene, selenium, zinc) }\end{array}$ \\
\hline Skin cancer in women [57] & High-dose selenium \\
\hline Melanoma [58] & Beta-carotene \\
\hline Lung cancer in smokers [60] & High-dose vitamins B6 and B12 \\
\hline Lung cancer in smokers [61] & Ditam \\
\hline
\end{tabular}

[27]. These nutrients should be maintained within an optimal level of intake: not too low, but also not too high. In the case of specific nutrients, certain foods may contain high levels already. Adding a supplement in these cases may quickly lead to consumption above the upper tolerable limits and result in multiple adverse effects [28]. For example, the recommended daily value (DV) for selenium in a healthy adult is $200 \mu \mathrm{g}$, and the upper tolerable intake level (UL) is $400 \mu \mathrm{g}$ [27]. A single Brazil nut can contain up to $90 \mu \mathrm{g}$ of selenium [29]. These values demonstrate the risk of a supplement containing the recommended DV in conjunction with just 3 Brazil nuts $(270 \mu \mathrm{g})$. This combination exceeds the established UL, increasing the risk of adverse events.

Iron overload may occur even at low doses [18], raising concern about the risks of iron supplementation in conjunction with ingestion from high-iron foods.

\section{Drug Interactions}

Supplements may interact with many prescription medications and laboratory tests. One literature review documented over 1,400 unique interactions with over 200 herbs and supplements [30]. Since no formal surveillance programs are required for supplements, it is imperative that physicians be alert for new reports.
In fact, despite a long history of biotin use in skin, hair, and nail supplements (Figures 4 and 5), it was only in 2017 that the FDA issued a warning about its potential for interactions with laboratory testing [31]. Impacted tests included those testing for thyroid and cardiac function. In a clinical trial, subjects were tested with specific biotinylated immunoassays before and after taking biotin $10 \mathrm{mg}$ daily for 7 days. Biotin ingestion interfered with 9 out of 23 biotinylated immunoassays. Researchers found falsely decreased thyroid-stimulating hormone concentrations, raising the concern of misdiagnosing hyperthyroidism in a healthy individual, as well as falsely decreased NT-proBNP, a test used to help diagnose congestive heart failure [32]. Troponin levels, used to diagnose myocardial infarction, were also falsely decreased.

Another study evaluated the accuracy of urine pregnancy tests in women consuming biotin. In nonpregnant women who ingested biotin $10 \mathrm{mg}$ daily for 7 days, urine samples were tested with a qualitative b-hCG urine pregnancy test. After day 3, 3 out of 4 tests revealed the absence of a control line. In other words, certain urine pregnancy tests may not function in women consuming biotin [33].

Reports in cardiology journals caution against the use of saw palmetto in patients taking warfarin due to the potential impacts on bleeding time. Case reports have described 
excessive intraoperative bleeding during a craniotomy [34], intraoperative floppy iris syndrome during a cataract procedure [35], and hematuria and coagulopathy in one patient [36]. The risk factors, frequency, and extent of this effect is not known, as one study in 10 volunteers found that saw palmetto ingestion did not affect platelet function tests in this small group [37].

\section{Teratogenicity and Effects on the Reproductive System}

As current labeling laws in the United States do not require pregnancy category warnings on any supplements, physicians must counsel their patients of any potential teratogenicity risks. Saw palmetto (Serenoa repens) is one concerning supplement. This plant has a long history of use in Asia and among Native Americans, especially as a treatment for benign prostatic hypertrophy (BPH), and is frequently found in supplements advertised for that condition [38]. It inhibits 5-alpha-reductase, which prevents the conversion of testosterone to dihydrotestosterone $[39,40]$. Because of this ability, saw palmetto is also featured in a number of hair loss supplements advertised for hair loss in both men and women [20]. Saw palmetto, as a 5-alpha-reductase inhibitor, presents a severe teratogenicity risk. The administration of 5-alphareductase inhibitors to pregnant animals is associated with male offspring with abnormal male genitalia. Therefore, these drugs are labeled pregnancy category $\mathrm{X}$, the category of greatest concern for pregnant women, by pharmaceutical companies [38]. Due to a lack of labeling regulations, no such warning is required for supplements, despite a similarly demonstrated mechanism of action.

High doses of vitamin A are also teratogenic, with risk particularly high before the seventh week of pregnancy, at a time when some women may not be aware of their pregnancy. Among pregnant women who averaged more than 10,000 IU per day of vitamin A orally (in the form of retinoid compounds), approximately 1 in 57 had a malformation owing to the supplement [42]. Similarly high doses may be found in some dietary supplements advertised for skin benefits, as in certain acne supplements [44].

For many nutrients, the risks related to ingestion of high doses are not known and have not been studied systemically. Zinc is often used in acne supplements and is one such nutrient that warrants further study. In one study, elevated levels of zinc in umbilical cord blood were associated with adverse neonatal neurobehavioral development [45].

Melatonin is another concerning supplement. Although sold as a dietary supplement, melatonin is actually a hormone that has important effects on circadian rhythms. Animal studies have indicated that melatonin has profound effects on reproductive organs, leading to concerns regarding its long-term use in a pediatric population [46].

\section{Allergies}

Due to the lack of federal regulation, little is known about hypersensitivity reactions to supplements. Multiple supplement ingredients have been associated with both Stevens-Johnson syndrome and toxic epidermal necrolysis, including ascorbic acid and Chinese herbal supplements [47]. Diindolylmethane, sometimes used in acne supplements, has been associated with the severe systemic allergic reaction DRESS (drug reaction with eosinophilia and systemic symptoms) [48]. Cutaneous drug reactions and urticaria have been described in herbs used to treat skin conditions $[49,50]$.

Additives used in many supplements, including dyes and preservatives, are well-known triggers of allergic reactions. Such reactions include urticarial reactions, fixed drug reactions, generalized dermatitis, and even anaphylaxis $[50,51]$.

While the allergenicity of collagen powders derived from sources such as seafood is unknown, hydrolyzed fish collagen has been associated with anaphylaxis [52].

\section{Potential Cancer Risk}

The role of micronutrients in chemoprevention and carcinogenesis is not completely understood. Animal research suggested that antioxidants, including beta-carotene, vitamin E, vitamin $\mathrm{C}$ and others, could have a chemoprotective effect. Observational studies found that individuals who consumed diets high in fruits and vegetables containing antioxidants were at lower risk of multiple cancers $[53,54]$. These promising results have not been observed when supplemental doses of antioxidants (as opposed to dietary doses) have been evaluated in large, population-based RCTs. In fact, in some cases supplementation may increase cancer risk.

Many supplements marketed as skin, hair, and nail supplements contain high levels of micronutrients. Some contain high levels of vitamins A, B6, B12, E, and selenium, all of which have been associated with higher cancer risk in various groups.

UV radiation enhances the formation of cutaneous free radicals, which play a pivotal role in the development of skin cancer (SC). Dietary antioxidants (AOs) are important in neutralizing free radicals, but dose (dietary as opposed to supplemental) and timing is critical [55]. Research on small animal models suggested that AO supplementation could prevent the development of SC [56]. However, in 
much of this research, AO supplementation occurred before exposure to UV radiation. In human studies, by contrast, AO supplementation often occurs after years of exposure to UV light [57].

In fact, supplementation with high doses of AOs may prove detrimental. In one study, researchers evaluated the effects of a combination supplement that contained promising micronutrients in the hope that it would reduce the risk of SC in women aged 35-60. This supplement contained vitamin $\mathrm{C}$, vitamin $\mathrm{E}$, beta-carotene, selenium, and zinc. Unfortunately, the incidence rate of SC in women consuming this supplement was significantly higher than those who took a placebo [57]. Another study examined the effects of selenium exposure. In this epidemiological study, the incidence of melanoma was 4 times higher in individuals exposed to high selenium levels from the environment than unexposed individuals [58].

This association between high-dose micronutrient supplementation and increased risk of cancer has been noted for other cancers as well, including lung cancer. Male smokers who took beta-carotene, a precursor to vitamin A, were at increased risk for lung cancer and cardiovascular disease in comparison to a placebo group. In fact, the trial was stopped early because the mortality rate was $17 \%$ higher in the treatment group [59,60]. Another study examined the effects of vitamins B6 and B12 supplementation and found a 30\%$40 \%$ increased risk of lung cancer among male smokers [61].

In terms of other cancers, alpha-tocopherol (vitamin E) supplementation in healthy men increased the risk of prostate cancer by $17 \%$ [62]. Folic acid supplementation in healthy men also increased the risk of prostate cancer [63].

\section{Other Risks}

A wide variety of other risks has been described from skin, hair, and nail supplements. Some include well-known risks, such as sedation from melatonin. Less well-known risks include hair loss that may result from high levels of selenium, vitamin A, and vitamin E [17]. Ironically, these are often found in supplements marketed for use in hair loss [64].

Other reported reactions are due, not to side effects from the active ingredients, but rather to the quality of the formulation. Quality concerns are a major concern with supplements, as the FDA does not require any proof of quality prior to sale. While manufacturers are required to follow current FDA Good Manufacturing Practices, the FDA is only able to inspect a small fraction of facilities every year. For the fiscal year 2019, 51\% of dietary supplement manufacturing facilities in the US and abroad were cited for noncompliance with these practices [65]. Quality concerns are a serious issue, as multiple reports have described microbial contamination with bacteria [66] as well as with fungi [66,67]. Multiple studies have also reported adulteration with heavy metals, such as Ayurvedic medicines contaminated with lead, mercury, and arsenic [68], and collagen powders contaminated with cadmium [69]. Adulteration with prescription medications has also been described for multiple supplements [70].

In addition, labeling and manufacturing errors have led to serious side effects. A manufacturing error resulted in selenium supplements containing 200 times the labeled concentration, resulting in multiple cases of acute selenium toxicity [71], while a mislabeled and improperly formulated vitamin $\mathrm{D}$ supplement led to a patient consuming more than 1,000 times the recommended dosage [72].

\section{Conclusions}

In accordance with FDA regulation, all prescription drugs must include a package insert detailing black box warnings, potential risks, and pregnancy category warnings. Supplements lack all of these warnings. In addition, no post-marketing surveillance programs are required. The results of these programs with prescription medications demonstrate their importance in detecting infrequent but severe side effects. Such programs have led to recalls of multiple promising prescription medications, such as the antihistamine terfenadine, linked to serious cardiac arrhythmias from drug interactions [73] and the anti-obesity drugs fenfluramine and dexfenfluramine, recalled due to reports of heart valve damage [74].

In discussing the risks of dietary supplements, we emphasize that our understanding of their safety and risk profiles is incomplete. Physicians should be wary of the ever-growing supplement industry and encourage further research and regulation.

\section{References}

1. Bailey RL, Gahche JJ, Miller PE, Thomas PR, Dwyer JT. Why US adults use dietary supplements. JAMA Intern Med. 2013;173(5):355-361. DOI: 10.1001/ jamainternmed.2013.2299. PMID: 23381623.

2. Chen F, Du M, Blumberg JB, et al. Association among dietary supplement use, nutrient intake, and mortality among U.S. adults: a cohort study. Ann Intern Med. 2019;170(9):604-613. PMID: 30959527.

3. Kantor ED, Rehm CD, Du M, White E, Giovannucci EL. Trends in dietary supplement use among US adults from 1999-2012. JAMA. 2016;316(14):1464-1474. DOI: 10.1001/ jama.2016.14403. PMID: 27727382.

4. Bailey RL, Gahche JJ, Lentino CV, et al. Dietary supplement use in the United States, 2003-2006. J Nutr. 2011;141(2):261-266. DOI: 10.3945/jn.110.133025. PMID: 21178089.

5. Katta R, Huang S. Skin, Hair and nail supplements: an 
evidence-based approach. Skin Therapy Lett. 2019;24(5):7-13. PMID: 31584785.

6. U.S. Food and Drug Administration. Dietary Supplement Labeling Guide: Chapter IV. Nutrition Labeling. April 2005. Accessed March 27, 2020. http://www.fda.gov/food/dietarysupplements-guidance-documents-regulatory-information/ dietary-supplement-labeling-guide-chapter-iv-nutritionlabeling

7. U.S. Food and Drug Administration. CFR - Code of Federal Regulations Title 21. Updated April 1, 2019. Accessed March 27, 2020. https://www.accessdata.fda.gov/scripts/cdrh/cfdocs/ cfCFR/CFRSearch.cfm? $\mathrm{fr}=101.9$

8. U.S. Food and Drug Administration. Questions and Answers on Dietary Supplements. Accessed April 20, 2020. https:// www.fda.gov/food/information-consumers-using-dietarysupplements/questions-and-answers-dietary-supplements

9. U.S. Food and Drug Administration. Small Entity Compliance Guide: Label Warning Statements for Iron-Containing Supplements and Drugs. October 2003. Accessed April 19, 2020. https://www.fda.gov/regulatory-information/searchfda-guidance-documents/small-entity-compliance-guide-labelwarning-statements-iron-containing-supplements-and-drugs

10. Geller AI, Shehab N, Weidle NJ, et al. Emergency department visits for adverse events related to dietary supplements. N Engl J Med. 2015;373(16):1531-1540. DOI: 10.1056/ NEJMsa1504267. .

11. Punzalan C, Budnitz DS, Chirtel SJ, et al. Swallowing problems and dietary supplements: data from U.S. Food and Drug Administration Adverse Event Reports, 2006-2015. Ann Intern Med. 2019;171(10):771. DOI: 10.7326/M19-0947. PMID: $31426091 .$.

12. Lui MFG, Chow HKD, Wong WMK, Tsang WNW. Melatonin affects postural control in community-dwelling older adults while dual tasking: a randomized observation study. J Aging Phys Act. 2018:1-6. DOI: 10.1123/japa.2017-0312. PMID: 29809094.

13. Knight J, Madduma-Liyanage K, Mobley JA, Assimos DG, Holmes RP. Ascorbic acid intake and oxalate synthesis. Urolithiasis. 2016;44:289-97. DOI: 10.1007/s00240-0160868-7. PMID: 27002809.

14. Baxmann AC, de O.G. Mendonça C, Heilberg IP. Effect of vitamin $\mathrm{C}$ supplements on urinary oxalate and $\mathrm{pH}$ in calcium stone-forming patients. Kidney Int. 2003;63(3):1066-1071. DOI: 10.1046/j.1523-1755.2003.00815.x. PMID: 12631089.

15. Rees DC, Kelsey H, Richards JD. Acute haemolysis induced by high dose ascorbic acid in glucose-6-phosphate dehydrogenase deficiency. BMJ. 1993;306:841-842. DOI: 10.1136/ bmj.306.6881.841. PMID: 8490379.

16. Jansen T, Romiti R, Kreuter A, Altmeyer P. Rosacea fulminans triggered by high-dose vitamins B6 and B12. J Eur Acad Dermatol Venerol. 2001;15(5):484-485. DOI: 10.1046/j.14683083.2001.00308.x.

17. Guo EL, Katta R. Diet and hair loss: effects of nutrient deficiency and supplement use. Dermatol Pract Concept. 2017;7(1):1-10. DOI: 10.5826/dpc.0701a01. PMID: 28243487.

18. Coates TD, Carson S, Wood JC, Berdoukas V. Management of iron overload in hemoglobinopathies: what is the appropriate target iron level? Ann N Y Acad Sci. 2016;1368:95-106. DOI: 10.1111/nyas.13060. PMID: 27186942.

19. Wooltorton E. Too much of a good thing? Toxic effects of vitamin and mineral supplements. CMAJ. 2003;169(1):47-48. PMID: 12847042.

20. Nutrafol Core for Women I Nutrafol. Accessed March 20, 2020. https://nutrafol.com/nutrafol-core-for-women

21. Rayman MP, Winther KH, Pastor-Barriuso R, et al. Effect of long-term selenium supplementation on mortality: Results from a multiple-dose, randomised controlled trial. Free Radic Biol Med. 2018;127:46-54. DOI: 10.1016/j. freeradbiomed.2018.02.015. PMID: 29454039.

22. Bleys J, Navas-Acien A, Guallar E. Serum selenium and diabetes in U.S. adults. Diabetes Care. 2007;30(4):829-834. DOI: $10.2337 / \mathrm{dc} 06-1726$. PMID: 17392543.

23. Bleys J, Navas-Acien A, Stranges S, et al. Serum selenium and serum lipids in US adults. Am J Clin Nutr. 2008;88(2):416-423. DOI: $10.1093 /$ ajcn/88.2.416. PMID: 18689378.

24. Stranges S, Laclaustra M, Ji C, et al. Higher selenium status is associated with adverse blood lipid profile in British adults. $J$ Nutr. 2010;140:81-87. DOI: 10.3945/jn.109.111252. PMID: 19906812.

25. Stranges S, Marshall JR, Natarajan R, et al. Effects of longterm selenium supplementation on the incidence of type 2 diabetes: a randomized trial. Ann Intern Med. 2007;147:217. DOI: 10.7326/0003-4819-147-4-200708210-00175. PMID: 17620655.

26. Faghihi T, Radfar M, Barmal M, et al. A randomized, placebocontrolled trial of selenium supplementation in patients with type 2 diabetes: effects on glucose homeostasis, oxidative stress, and lipid profile. Am J Ther. 2014;21(6):491-495. DOI: 10.1097/MJT.0b013e318269175f. PMID: 23633679.

27. Nutrient Recommendations: Dietary Reference Intakes (DRI). n.d. Accessed April 19, 2020. https://ods.od.nih.gov/Health_ Information/Dietary_Reference_Intakes.aspx

28. Institute of Medicine (US) Subcommittee on Interpretation and Uses of Dietary Reference. Using the Tolerable Upper Intake Level for Nutrient Assessment of Groups. DRI Dietary Reference Intakes: Applications in Dietary Assessment. National Academies Press (US); 2000. https://www.ncbi.nlm. nih.gov/books/NBK222879/

29. Parekh PP, Khan AR, Torres MA, Kitto ME. Concentrations of selenium, barium, and radium in Brazil nuts. Journal of Food Composition and Analysis. 2008;21(4):332-335. DOI: 10.1016/j.jfca.2007.12.001.

30. Fugh-Berman A. Herb-drug interactions. Lancet. 2000;355:134-138. DOI: 10.1016/S0140-6736(99)06457-0. PMID: 10675182.

31. The FDA Warns that Biotin May Interfere with Lab Tests: FDA Safety Communication. FDA. November 28, 2017. Accessed April 16, 2020. https://www.fda.gov/medical-devices/safetycommunications/fda-warns-biotin-may-interfere-lab-tests-fdasafety-communication

32. Li D, Radulescu A, Shrestha RT, et al. Association of biotin ingestion with performance of hormone and nonhormone assays in healthy adults. JAMA. 2017;318(12):1150-1160. DOI: 10.1001/jama.2017.13705. PMID: 28973622.

33. Williams GR, Cervinski MA, Nerenz RD. Assessment of biotin interference with qualitative point-of-care hCG test devices. Clin Biochem. 2018;53:168-170. DOI: 10.1016/j. clinbiochem.2018.01.018. PMID: 29395091].

34. Cheema P, El-Mefty O, Jazieh AR. Intraoperative haemorrhage associated with the use of extract of Saw Palmetto herb: a case 
report and review of literature. J Intern Med. 2001;250:167-9. DOI: 10.1046/j.1365-2796.2001.00851.x. PMID: 29395091.

35. Yeu E, Grostern R. Saw palmetto and intraoperative floppyiris syndrome. J Cataract Refract Surg. 2007;33(5):927-928. 10.1016/j.jcrs.2006.12.032. PMID: 17466877.

36. Villanueva S, González J. Coagulopathy induced by saw palmetto: a case report. Bol Asoc Med P R. 2009;101:48-50. PMID: 20120986.

37. Beckert BW, Concannon MJ, Henry SL, Smith DS, Puckett CL. The effect of herbal medicines on platelet function: an in vivo experiment and review of the literature. Plast Reconstr Surg. 2007;120(7):2044-2050. 10.1097/01. prs.0000295972.18570.0b. PMID: 18090773.

38. Appendix K. Prototype Focused Monograph: Review of Antiandrogenic Risks of Saw Palmetto Ingestion by Women. In: Dietary Supplements: A Framework for Evaluating Safety. Institute of Medicine (US) and National Research Council (US) Committee on the Framework for Evaluating the Safety of Dietary Supplements. National Academies Press; 2005. Accessed December 13, 2019. https://www.ncbi.nlm.nih.gov/ books/NBK216069/

39. Veltri RW, Marks LS, Miller MC, et al. Saw palmetto alters nuclear measurements reflecting DNA content in men with symptomatic BPH: evidence for a possible molecular mechanism. Urology. 2002;60(4):617-622. DOI: 10.1016/ S0090-4295(02)01838-1. PMID: 12385921.

40. Di Silverio F, Monti S, Sciarra A, et al. Effects of longterm treatment with Serenoa repens (Permixon $®$ ) on the concentrations and regional distribution of androgens and epidermal growth factor in benign prostatic hyperplasia. Prostate. 1998;37(2):77-83. DOI: 10.1002/(SICI)10970045(19981001)37:2<77::AID-PROS3>3.0.CO;2-I. PMID: 9759701.

41. Miller RK, Hendrickx AG, Mills JL, Hummler H, Wiegand U. Periconceptional vitamin A use: how much is teratogenic? Reprod Toxicol. 1998;12(1):75-88. DOI: 10.1016/S08906238(97)00102-0. PMID: 9431575.

42. Rothman KJ, Moore LL, Singer MR, et al. Teratogenicity of high vitamin A intake. N Engl J Med. 1995;333:1369-1173. DOI: 10.1056/NEJM199511233332101. PMID: 7477116.

43. Martínez-Frías ML, Salvador J. Epidemiological aspects of prenatal exposure to high doses of vitamin A in Spain. Eur J Epidemiol. 1990;6(2):118-123. DOI: 10.1007/BF00145783. PMID: 2361535.

44. Derma Drink. Accessed March 30, 2020. https://dermadrink. com/products/derma-drink

45. Yang X, Yu X, Fu H, Li L, Ren T. Different levels of prenatal zinc and selenium had different effects on neonatal neurobehavioral development. Neurotoxicology. 2013;37:3539. DOI: 10.1016/j.neuro.2013.04.001. PMID: 23570748.

46. Kennaway DJ. Potential safety issues in the use of the hormone melatonin in paediatrics. J Paediatr Child Health. 2015;51(6):584-589. DOI: 10.1111/jpc.12840. PMID: 25643981.

47. Blumenthal KG, Wickner PG, Lau JJ, Zhou L. Stevens-Johnson syndrome and toxic epidermal necrolysis: A cross-sectional analysis of patients in an integrated allergy repository of a large health care system. J Allergy Clin Immunol Pract. 2015;3(2):277-280.e1. DOI: 10.1016/j.jaip.2014.10.002. PMID: 25609329.
48. Le T-M, Sanders CJG, van de Corput L, van Erpecum KJ, Röckmann H. Drug rash with eosinophilia and systemic symptoms caused by the dietary supplement diindolylmethane. J Allergy Clin Immunol Pract. 2016;4(1):175-176. DOI: 10.1016/j.jaip.2015.07.007. PMID: 26298826.

49. Witkowski JA, Parish LC. Dermatologic manifestations of complementary therapy. Skinmed. 2003;2(3):175-180. DOI: 10.1111/j.1540-9740.2003.02166.x. PMID: 14673295.

50. Andreozzi L, Giannetti A, Cipriani F, Caffarelli C, Mastrorilli C, Ricci G. Hypersensitivity reactions to food and drug additives: problem or myth? Acta Biomed. 2019;90(3-S):80-90. DOI: 10.23750/abm.v90i3-S.8168. PMID: 30830065.

51. Swerlick RA, Campbell CF. Medication dyes as a source of drug allergy. J Drugs Dermatol. 2013;12(1):99-102. PMID: 23377335.

52. Fujimoto W, Fukuda M, Yokooji T, Yamamoto T, Tanaka A, Matsuo H. Anaphylaxis provoked by ingestion of hydrolyzed fish collagen probably induced by epicutaneous sensitization. Allergol Int. 2016;65(4):474-476. DOI: 10.1016/j. alit.2016.03.012. PMID: 27569115.

53. Byers T, Perry G. Dietary carotenes, vitamin C, and vitamin $\mathrm{E}$ as protective antioxidants in human cancers. Annu Rev Nutr. 1992;12:139-159. DOI: 10.1146/annurev. nu.12.070192.001035. PMID: 1503801.

54. Martínez ME, Jacobs ET, Baron JA, Marshall JR, Byers T. Dietary supplements and cancer prevention: balancing potential benefits against proven harms. J Natl Cancer Inst. 2012;104:732-9. DOI: 10.1093/jnci/djs195. PMID: 22534785.

55. Katta R, Brown DN. Diet and skin cancer: The potential role of dietary antioxidants in nonmelanoma skin cancer prevention. J Skin Cancer. 2015;2015:8933149. DOI: 10.1155/2015/893149. PMID: 26583073.

56. Sander CS, Chang H, Hamm F, Elsner P, Thiele JJ. Role of oxidative stress and the antioxidant network in cutaneous carcinogenesis. Int J Dermatol. 2004;43(5):326-335. DOI: 10.1111/j.1365-4632.2004.02222.x. PMID: 15117361.

57. Hercberg S, Ezzedine K, Guinot C, et al. Antioxidant supplementation increases the risk of skin cancers in women but not in men. J Nutr. 2007;137(9):2098-2105. DOI: 10.1093/ jn/137.9.2098. PMID: 17709449.

58. Vinceti M, Rothman KJ, Bergomi M, Borciani N, Serra L, Vivoli G. Excess melanoma incidence in a cohort exposed to high levels of environmental selenium. Cancer Epidemiol Biomarkers Prev. 1998;7(10):853-856. PMID: 9796628.

59. Omenn GS, Goodman GE, Thornquist MD, et al. Effects of a combination of beta carotene and vitamin A on lung cancer and cardiovascular disease. N Engl J Med. 1996;334:1150-11155. DOI: 10.1056/NEJM199605023341802. PMID: 8602180.

60. Goodman GE, Thornquist MD, Balmes J, et al. The betacarotene and retinol efficacy trial: incidence of lung cancer and cardiovascular disease mortality during 6-year follow-up after stopping $\beta$-carotene and retinol supplements. J Natl Cancer Inst. 2004;96(23):1743-1750. DOI: 10.1093/jnci/djh320. PMID: 15572756.

61. Brasky TM, White E, Chen C-L. Long-term, supplemental, one-carbon metabolism-related vitamin $\mathrm{b}$ use in relation to lung cancer risk in the Vitamins and Lifestyle (VITAL) Cohort. J Clin Oncol. 2017;35(30):3440-3448. DOI: 10.1200/ JCO.2017.72.7735. PMID: 28829668.

62. Klein EA, Thompson IM, Tangen CM, et al. Vitamin E and 
the risk of prostate cancer: the Selenium and Vitamin E Cancer Prevention Trial (SELECT). JAMA. 2011;306(14):1549. DOI: 10.1001/jama.2011.1437. PMID: 21990298.

63. Wien TN, Pike E, Wisløff T, Staff A, Smeland S, Klemp M. Cancer risk with folic acid supplements: a systematic review and meta-analysis. BMJ Open. 2012;12(1):e000653. DOI: 10.1136/bmjopen-2011-000653. PMID: 22240654.

64. Nutrafol Ingredients. Accessed April 15, 2020. https://nutrafol. com/ingredients/.

65. FDA Finds Problems at $52 \%$ of Supplement Manufacturing Sites in U.S. and $42 \%$ Abroad. ConsumerLabCom. March 13, 2020. Accessed March 30, 2020. https://www. consumerlab.com/recall_detail.asp? recallid $=14344 \& j=131$ 0544\&sfmc_sub=119745391\&l=529_HTML\&u=180204 $88 \& \mathrm{mid}=7276525 \& \mathrm{jb}=372 \&$ utm_medium $=$ email $\&$ utm source $=$ exacttarget $\& u t m_{-}$campaign $=$newsletter $\& u t m$ term=\&utm_content=holy_basil_non_member_de_send

66. Dlugaszewska J, Ratajczak M, Kamińska D, Gajecka M. Are dietary supplements containing plant-derived ingredients safe microbiologically? Saudi Pharm J. 2019;27(2):240-245. DOI: 10.1016/j.jsps.2018.11.005. PMID: 30766436.

67. Fatal Gastrointestinal Mucormycosis in an Infant Following Use of Contaminated ABC Dophilus Powder From Solgar Inc. Fungal Diseases. CDC.gov. February 20, 2015. Accessed April 13, 2020. https://www.cdc.gov/fungal/outbreaks/rhizopusinvestigation.html

68. Saper RB, Phillips RS, Sehgal A, et al. Lead, mercury, and arsenic in US- and Indian-manufactured Ayurvedic medicines sold via the Internet. JAMA. 2008;300:915-23. DOI: 10.1001/ jama.300.8.915. PMID: 18728265.

69. ConsumerLab Reveals Best Collagen Supplements. ConsumerLabCom. October 4, 2019. Accessed April 13, 2020. https://www.consumerlab.com/news/consumerlab-tests-revealbest-collagen-supplements/10-04-2019/

70. Tucker J, Fischer T, Upjohn L, Mazzera D, Kumar M. Unapproved pharmaceutical ingredients included in dietary supplements associated with US Food and Drug Administration warnings. JAMA Netw Open. 2018;1(6):e183337. DOI: 10.1001/jamanetworkopen.2018.3337. PMID: 30646238.

71. MacFarquhar JK, Broussard DL, Melstrom P, et al. Acute selenium toxicity associated with a dietary supplement. Arch Intern Med. 2010;170(3):256-261. DOI: 10.1001/ archinternmed.2009.495. PMID: 20142570.

72. Araki T, Holick MF, Alfonso BD, et al. Vitamin D intoxication with severe hypercalcemia due to manufacturing and labeling errors of two dietary supplements made in the United States. J Clin Endocrinol Metab. 2011;96(12):3603-3608. DOI: 10.1210/jc.2011-1443. PMID: 21917864.

73. US Food and Drug Administration. Ventricular Arrhythmia (Torsades de Pointes) Occurring in Association with Terfenadine Use. April 6, 2016. Accessed April 13, 2020. https://www.fda. gov/drugs/drug-interactions-labeling/ventricular-arrhythmiatorsades-de-pointes-occurring-association-terfenadine-use

74. Anti-obesity drugs recalled from global market. The Lancet. 1997;350:867. DOI: 10.1016/S0140-6736(97)23038-2. 